\title{
Effects of Edible Coating on the Quality Change in 'Hongro' Apples during Storage
}

\author{
Jihyun Lee - Sea C. Min · Kyung Bin Song* \\ 가식성 코팅이 '홍로' 사과 저장 중 품질변화에 미치는 영향 \\ 이지현 · 민세철 · 송경빈*
}

Received: 4 October 2014 / Accepted: 5 January 2015 / Published Online: 31 March 2015

(C) The Korean Society for Applied Biological Chemistry 2015

\begin{abstract}
As an edible coating, carnauba shellac wax (CSW) and lemongrass oil (LO) solution was prepared to extend the shelf life of 'Hongro' apples. During storage, there were significant differences in the populations of total aerobic bacteria, yeast, and molds between the coated apples and the control samples. The weight loss and vitamin C loss of apples coated with the CSW-LO solution were lower than those of the control. These results suggest that CSW-LO coating can be an effective method for improving quality of 'Hongro' apples.
\end{abstract}

Keywords edible coating $\cdot$ Hongro apple $\cdot$ quality change $\cdot$ storage

가식성 코팅은 수분손실, 기체투과도, 호흡률 등을 낮추고, 다 양한 항균, 항산화 물질 등을 첨가하여 미생물의 변패로부터 식 품을 보호할 수 있어 유통기한을 연장시킬 수 있다(Elsabee와 Abdou, 2013). 항균성 물질로는 유기산, 지방산 에스테르, 식물 essential oil 등을 첨가할 수 있는데(Mantilla 등, 2013), 그 중

\section{J. Lee $\cdot$ K. B. Song}

Department of Food Science and Technology, Chungnam National University, Daejeon 305-764, Republic of Korea

\section{S. C. Min}

Department of Food Science and Technology, Seoul Women's University, Seoul 139-774, Republic of Korea

\section{*Corresponding author (K. B. Song: kbsong@cnu.ac.kr)}

This is an Open Access article distributed under the terms of the Creative Commons Attribution Non-Commercial License (http://creativecommons. org/licenses/by-nc/3.0/) which permits unrestricted non-commercial use, distribution, and reproduction in any medium, provided the original work is properly cited. lemongrass oil (LO)은 항균성과 더불어 바람직한 향을 가지고 있어 과일코팅에 적합하다. 왁스를 이용한 가식성 코팅은 중량 감소 및 곰팡이 생육 저해, 숙성 지연 등 식품의 저장성 증진 뿐만 아니라 식품의 외관 또한 개선할 수 있어(Parra 등, 2014), 최근 과일 코팅에 사용되어 저장 기간을 연장시키는 효과가 보 고되었다(Mehyar 등, 2014). 한국에서 재배되는 사과 품종 중 후지가 $62.6 \%$, 홍로가 $14.8 \%$ 를 차지하고 있는데, 후지의 경우 저온저장 시 5-6개월 보관이 가능하다(Park과 Park, 2012). 반 면에 홍로는 저온저장 시 3개월 정도 저장이 가능하여 '후지' 보다 저장성이 떨어지는 문제가 있다(Park 등, 2009).

따라서 본 연구에서는 '홍로' 사과의 저장성을 증진시키기 위 해서, $\mathrm{CSW}$ 와 CSW-LO를 이용한 '후지' 사과 코팅 관련 이전 연구결과(Jo 등, 2014)를 토대로, '후지'와는 다른 특성을 갖는 '홍로' 사과의 저장 중 품질 변화에 CSW-LO 가식성 코팅제의 사용이 끼치는 영향을 분석하고자 수행하였다.

본 연구에서 사용된 사과는 전북 장수에서 수확한 '홍로' 품 종으로 숙성 정도, 색 등이 일정한 것을 골라 수확 후 바로 실 험에 사용하였다. 이전 연구보고(Jo 등, 2014)와 예비실험 결과 를 바탕으로, CSW-LO 코팅용액을 제조하였다. CSW에 $0.5 \%$ $(\mathrm{v} / \mathrm{v}) \mathrm{LO}$ 를 첨가한 후, Tween 20 을 $\mathrm{LO}$ 의 $25 \%$ 되게 첨가하여 30 분간 섞어주었다. 또한 균일한 용액 제조를 위해 homogenizer (IKA, Ultra-Turrax T25 Digital, Staufen, Germany)와 sonicator (Model-GE 750, Sonics \& Materials, Newtown, USA)를 이 용하여 균질화하였다. 사과 코팅을 위해 제조된 CSW-LO 코팅 용액에 사과를 2 분간 침지하고, hood에서 10 분간 건조한 후, 코 팅하지 않은 사과와 각각 $1 \pm 1^{\circ} \mathrm{C}$ 가 유지되는 cold chamber에서 12 주 동안 저장하면서 3 주마다 미생물 수와 품질변화를 측정하 였다.

그 결과 저장 중 총 호기성 세균과 효모 및 곰팡이 수는 증 가하는 경향을 보였으며, 저장 초기 대조구의 총 호기성 세균 은 $2.69 \log \mathrm{CFU} / \mathrm{g}, \mathrm{CSW}-\mathrm{LO}$ 로 코팅한 '홍로' 사과의 경우 $1.80 \log \mathrm{CFU} / \mathrm{g}$ 으로 나타났고, 효모 및 곰팡이의 경우도 각각 
Table 1 Changes in the populations $(\log \mathrm{CFU} / \mathrm{g})$ of total aerobic bacteria and yeast and molds in the 'Hongro' apples during storage

\begin{tabular}{|c|c|c|c|c|}
\hline \multirow{2}{*}{ Storage time (week) } & \multicolumn{2}{|c|}{ Total aerobic bacteria } & \multicolumn{2}{|c|}{ Yeast and molds } \\
\hline & Control & Edible coating $^{1)}$ & Control & Edible coating \\
\hline 0 & $2.69 \pm 0.20^{\mathrm{Ac} 2)}$ & $1.80 \pm 0.10^{\mathrm{Bbc}}$ & $2.72 \pm 0.21^{\mathrm{Ab}}$ & $2.15 \pm 0.35^{\mathrm{Ba}}$ \\
\hline 3 & $2.64 \pm 0.27^{\mathrm{Ac}}$ & $2.08 \pm 0.42^{\mathrm{Ba}}$ & $2.61 \pm 0.27^{\mathrm{Ab}}$ & $1.65 \pm 0.11^{\mathrm{Bb}}$ \\
\hline 6 & $2.77 \pm 0.46^{\mathrm{Ac}}$ & $1.63 \pm 0.11^{\mathrm{Bc}}$ & $2.74 \pm 0.22^{\mathrm{Ab}}$ & $2.13 \pm 0.19^{\mathrm{Ba}}$ \\
\hline 9 & $3.47 \pm 0.11^{\mathrm{Ab}}$ & $1.65 \pm 0.21^{\mathrm{Bbc}}$ & $3.44 \pm 0.28^{\mathrm{Aa}}$ & $1.82 \pm 0.39^{\mathrm{Ba}}$ \\
\hline 12 & $4.02 \pm 0.02^{\mathrm{Aa}}$ & $1.99 \pm 0.09^{\mathrm{Bab}}$ & $3.54 \pm 0.12^{\mathrm{Aa}}$ & $1.88 \pm 0.25^{\mathrm{Ba}}$ \\
\hline
\end{tabular}

${ }^{1)}$ Carnauba-shellac wax containing $0.5 \%$ lemongrass oil.

${ }^{2}$ Mean values of different letters within a column (a-c) or row (A-B) are significantly different by Duncan's multiple range test at $p<0.05$.

Table 2 Changes in hardness and weight loss of 'Hongro' apples during storage

\begin{tabular}{ccccc}
\hline \multirow{2}{*}{ Storage time (week) } & \multicolumn{2}{c}{ Hardness $(\mathrm{N})$} & Control & Weight loss (\%) \\
\cline { 2 - 5 } & Control & Edible coating & - & - \\
\hline 0 & $18.37 \pm 1.29^{\mathrm{Aa} 2)}$ & $18.11 \pm 2.17^{\mathrm{Aa}}$ & $2.25 \pm 0.46^{\mathrm{Ac}}$ & $1.13 \pm 0.01^{\mathrm{Ac}}$ \\
3 & $17.01 \pm 1.81^{\mathrm{Ab}}$ & $17.84 \pm 1.11^{\mathrm{Aa}}$ & $4.42 \pm 0.68^{\mathrm{Ab}}$ & $1.93 \pm 0.02^{\mathrm{Bbc}}$ \\
6 & $16.49 \pm 1.10^{\mathrm{Ab}}$ & $17.23 \pm 0.66^{\mathrm{Aa}}$ & $5.54 \pm 0.86^{\mathrm{Aab}}$ & $2.57 \pm 0.01^{\mathrm{Bb}}$ \\
9 & $16.22 \pm 0.43^{\mathrm{Ab}}$ & $17.65 \pm 0.68^{\mathrm{Aa}}$ & $6.58 \pm 1.10^{\mathrm{Aa}}$ & $3.37 \pm 0.30^{\mathrm{Ba}}$ \\
\hline
\end{tabular}

${ }^{1)}$ Carnauba-shellac wax containing $0.5 \%$ lemongrass oil.

${ }^{2}$ Mean values of different letters within a column (a-c) or row (A-B) are significantly different by Duncan's multiple range test at $p<0.05$.

2.72, $2.15 \log \mathrm{CFU} / \mathrm{g}$ 이었다(Table 1). 저장 중 코팅하지 않은 '홍로' 사과의 총 호기성 세균과 효모 및 곰팡이 수는 CSW-LO 로 코팅한 군과 유의적인 차이를 보였는데, 저장 12 주차 코팅 하지 않은 사과의 총 호기성 세균은 $4.02 \log \mathrm{CFU} / \mathrm{g}$, 효모 및 곰팡이는 $3.54 \log \mathrm{CFU} / \mathrm{g}$ 인 반면에, CSW-LO로 코팅한 사과의 경우 $1.99,1.88 \log \mathrm{CFU} / \mathrm{g}$ 으로 각각 $2.03,1.66 \log \mathrm{CFU} / \mathrm{g}$ 의 감균효과를 가졌다. 이러한 결과는 Kim 등(2013)의 CSW-LO 코팅이 저장 중 자두의 병원성 미생물의 생장을 억제하였다는 보고와 유사하였다. 코팅에 의한 감균 효과는 $\mathrm{CSW}$ 와 $\mathrm{LO}$ 의 항 균효과에 의한 것인데, $\mathrm{CSW}$ 는 당의 결핍을 야기하여 미생물 생장을 억제하고, 그 구성성분인 4-hydroxycinnamic acid 등이 항균효과를 가진다고 보고되었다(Jo 등, 2014; Mehyar 등, 2014). 특히 LO는 terpene류가 미생물의 세포막으로 확산되면서 막 구조에 영향을 주어 다양한 미생물에 대한 항균성을 나타내 기에(Mpho 등, 2013), CSW-LO 코팅이 저장 중 '홍로' 사과의 미생물 생육을 억제하는 효과가 저장 중 지속된다고 판단된다.

또한 저장 중 사과의 품질변화 측정을 위해 당도, 산도, 경 도, 중량감소율 및 비타민 $\mathrm{C}$ 함량을 측정하여 저장 중 변화를 관찰하였다. 당도와 산도는 분쇄된 사과를 거즈에 걸러 각각 당 도계(PR-101 $\alpha$, Atago, Japan)와 $0.1 \mathrm{~N} \mathrm{NaOH}$ 를 이용한 적정방 법을 통해 측정하였다. 측정결과 코팅되지 않은 '홍로' 사과의 경우 저장 기간에 따라 산도가 감소하는 경향을 보였으며, CSW-LO 코팅된 사과의 경우 6 주차까지는 0.41 에서 $0.46 \%$ 로 증가하였다가 그 이후에는 비슷한 값을 유지하였다(data not shown). 저장 중 '홍로' 사과의 산도 감소는 malic acid가 대사 산물로 사용되었기 때문이다(Ackermann 등, 1992). 당도의 경 우 코팅되지 않은 사과는 저장 중 계속 증가하다가 9주차에 약 간 감소하였으며, $\mathrm{CSW}-\mathrm{LO}$ 로 코팅한 사과의 경우 저장 중 큰 변화를 보이지 않았다. 당도의 경우 과일의 숙성 중 호흡작용 에 의해 저장 중 증가하는 경향을 보이는데, Duan 등(2011)에 의해 calcium caseinate, chitosan 등 다양한 가식성 코팅 처리
된 블루베리 저장 중 당도는 코팅처리에 크게 영향을 받지 않 았다는 보고와 유사하였다. 따라서 가식성 코팅 처리는 저장 중 ‘홍로' 사과의 산도 및 당도변화에 크게 영향을 끼치지 않는다 고 판단되며, 이전의 ‘후지' 사과의 연구결과와도 일치하여 비 록 품종이 다르고 수확 후 생리가 다르더라도 가식성 코팅은 저장 중 사과의 품질 유지 측면에서 바람직한 수확 후 기술이 라고 사료된다.

사과의 경도는 texture analyzer (TA-XT2, Stable Microsystem Ltd., UK)를 이용하여 측정하였는데, 코팅하지 않은 사과에서는 저장기간 내내 감소가 나타난 반면에, CSW-LO로 코팅한 사과 의 경우 큰 변화를 보이지 않다가 저장 9주차 이후로 약간의 감소를 보였다(Table 2). 이는 chitosan 코팅이 사과의 표면에 필름을 형성하여 수분손실을 막고 호흡을 조절하여 저장 중 사 과의 경도를 유지시켰다는 Shao 등(2012)의 결과와도 일치한다. 코팅되지 않은 사과의 경도는 0주차에 $18.37 \mathrm{~N}$ 으로 CSW-LO로 코팅한 사과와 큰 차이를 보이지 않았으나, 12 주 저장 후 14.56 $\mathrm{N}$ 으로 $3.79 \mathrm{~N}$ 의 감소가 나타났다. 이에 반해 CSW-LO로 코팅 된 사과의 경우 $1.08 \mathrm{~N}$ 의 감소를 보였다. 이러한 결과는 코팅 되지 않은 사과에서 수분이 증발하였고, 저장 중 사과의 호흡 작용으로 인한 숙성으로 사과의 세포벽에 존재하는 펙틴의 구 조적인 변화에 의해 사과가 약해졌기 때문이라고 판단된다 (Gwanpua 등, 2014). 일반적으로 과일의 숙성 중 경도가 감소 하는 경향을 보이는데, CSW-LO 코팅한 사과에서는 LO가 사 과의 세포막과의 반응을 통해 호흡 작용에 영향을 미쳐 과일의 숙성을 지연시켰기 때문에 사과의 경도를 유지하였다고 판단된 다(Perdones 등, 2012). 또한 저장 중 가식성 필름으로 코팅된 '홍로' 사과의 중량 감소율에 관한 연구결과(Table 2), 12주 저 장 동안 모두 중량이 감소하였는데 코팅되지 않은 사과의 경우 다른 군에 비해 감소 속도가 빠르게 나타났다. 대조구의 중량 감소율은 저장기간에 따라 유의적으로 증가하였고, CSW-LO 코 팅한 '홍로' 사과의 경우 저장 12 주차 중량이 $3.37 \%$ 가 감소한 
Table 3 Changes in vitamin C content (mg ascorbic acid/100 g) in the peel and flesh of the 'Hongro' apples during storage

\begin{tabular}{|c|c|c|c|c|}
\hline \multirow{2}{*}{ Storage time (week) } & \multicolumn{2}{|c|}{ Peel } & \multicolumn{2}{|c|}{ Flesh } \\
\hline & Control & Edible coating $^{1)}$ & Control & Edible coating \\
\hline 0 & $10.37 \pm 0.74^{\mathrm{Aa} 2)}$ & $11.03 \pm 0.38^{\mathrm{Aa}}$ & $6.68 \pm 0.60^{\mathrm{Aa}}$ & $6.60 \pm 0.11^{\text {Aab }}$ \\
\hline 3 & $10.17 \pm 0.28^{\mathrm{Aa}}$ & $10.64 \pm 0.48^{\mathrm{Aba}}$ & $6.54 \pm 0.18^{\mathrm{Aa}}$ & $6.71 \pm 0.06^{\mathrm{Aa}}$ \\
\hline 6 & $9.64 \pm 0.17^{\mathrm{ABab}}$ & $11.60 \pm 0.63^{\mathrm{Aba}}$ & $6.73 \pm 0.12^{\mathrm{Aa}}$ & $6.91 \pm 0.29^{\mathrm{Aa}}$ \\
\hline 9 & $8.70 \pm 0.30^{\mathrm{Abc}}$ & $9.85 \pm 0.64^{\mathrm{Abc}}$ & $5.89 \pm 0.24^{\mathrm{Ab}}$ & $6.51 \pm 0.39^{\mathrm{Aab}}$ \\
\hline 12 & $8.12 \pm 0.17^{\mathrm{Bc}}$ & $9.15 \pm 0.01^{\mathrm{Ac}}$ & $5.88 \pm 0.03^{\mathrm{Ab}}$ & $6.21 \pm 0.37^{\mathrm{Ab}}$ \\
\hline
\end{tabular}

${ }^{1)}$ Carnauba-shellac wax containing $0.5 \%$ lemongrass oil.

${ }^{2)}$ Mean values of different letters within a column (a-c) or row (A-B) are significantly different by Duncan's multiple range test at $p<0.05$.

데 반해 코팅되지 않은 사과의 경우 $6.58 \%$ 의 감소가 나타났다. Zambrano-Zaragoza 등(2013)은 구아바에 $60 \mathrm{~g} / \mathrm{L}$ solid lipid nanoparticles을 함유한 $\mathrm{CSW}$ 를 이용하여 코팅한 결과 대조구에 비해 낮은 중량감소율을 나타냈는데, 이는 저장 중 코팅액이 과 일의 수분 증발을 막았기 때문이라고 보고하였다. 대조구에 비 해 CSW-LO 코팅한 ‘홍로' 사과에서 낮은 중량감소율이 나타 난 것은 $\mathrm{LO}$ 의 첨가로 코팅액의 소수성이 증가하고 이로 인해 수분 증발에 대한 저항성이 커져 water barrier 특성에 의해 낮 은 중량 감소율을 보였다고 판단된다(Sánchez-González 등, 2011). 따라서 CSW-LO 코팅은 '홍로' 사과의 수분 증발과 호 흡작용에 의한 경도 및 중량감소를 방지할 수 있어 효과적인 사과 코팅제로 사용할 수 있다고 생각된다.

저장 중 비타민 $\mathrm{C}$ 함량은 껍질과 과육 모두 감소하는 경향 을 보였는데(Table 3), 특히 코팅한 사과의 비타민 C 함량이 대 조구에 비해 감소율이 낮았다. 초기 비타민 $\mathrm{C}$ 함량과 비교하였 을 때 12 주 후에는 대조구의 비타민 $\mathrm{C}$ 함량은 껍질, 과육에서 각각 $2.3,0.8 \mathrm{mg}$ ascorbic acid/ $100 \mathrm{~g}$ 감소한 반면에, 코팅한 사과에서는 $1.9,0.4 \mathrm{mg}$ ascorbic acid/100 g 감소하였다. 비타민 $\mathrm{C}$ 감소는 산소의 유무에 영향을 받기 때문에 CSW-LO 코팅이 산소의 확산을 막아 비타민 $\mathrm{C}$ 감소를 지연시키는 역할을 했다 고 판단된다(Abbasi 등, 2009). 또한 $\mathrm{LO}$ 의 페놀 화합물의 항산 화 효과 때문에 비타민 $\mathrm{C}$ 함량이 더욱 유지되었다고 판단된다 (Xing 등, 2011). 이와 유사하게 Barman 등(2014)도 putrescine 과 $\mathrm{CSW}$ 로 코팅한 석류 저장 중 $\mathrm{CSW}$ 가 석류의 호흡률을 낮 춰주어 대조구에 비해 비타민 $\mathrm{C}$ 함량을 유지하였다고 보고하 였다.

이상의 결과들로부터 CSW-LO 코팅은 저장 중 ‘홍로' 사과 의 미생물학적 안전성과 품질을 유지하는데 효과적임을 확인할 수 있었다. 따라서 CSW-LO 코팅액은 사과의 저장 안전성을 높 이고 유통기한을 연장시킬 수 있을 것으로 판단된다.

\section{초 록}

CSW-LO 코팅액으로 코팅된 '홍로' 사과의 저장 중 미생물 수 및 품질 변화를 측정한 결과 대조구와 코팅된 사과의 총 호기 성 세균과 효모 및 곰팡이 수는 유의적인 차이를 보였다. 또한 처리구의 경도, 중량감소, 비타민 $\mathrm{C}$ 함량은 저장 중 대조구에 비해 더 낮은 감소를 보였다. 따라서 CSW-LO 코팅은 '홍로' 사과의 저장 중 미생물학적 안전성과 품질유지에 효과적인 수 확 후 처리라고 판단된다.
Keywords 가식성코팅 - 저장 - 품질변화 - 홍로 사과

\section{References}

Abbasi NA, Iqbal Z, Maqbool M, and Hafiz IA (2009) Postharvest quality of mango (Mangifera indica L.) fruit as affected by chitosan coating. Pak $J$ Bot 41, 343-57.

Ackermann J, Fischer M, and Amado R (1992) Changes in sugars, acids, and amino acids during ripening and storage of apples (cv. Glockenapfel). $J$ Agr Food Chem 40, 1131-4.

Barman K, Asrey R, Pal RK, Kaur C, and Jha SK (2014) Influence of putrescine and carnauba wax on functional and sensory quality of pomegranate (Punica granatum L.) fruits during storage. J Food Sci Technol 51, 111-7.

Duan J, Wu R, Strik BC, and Zhao Y (2011) Effect of edible coatings on the quality of fresh blueberries (Duke and Elliott) under commercial storage conditions. Postharvest Biol Tec 59, 71-9.

Elsabee MZ and Abdou ES (2013) Chitosan based edible films and coatings: A review. Mater Sci Eng: C 33, 1819-41.

Gwanpua SG, Van Buggenhout S, Verlinden BE, Christiaens S, Shpigelman A, Vicent V et al. (2014) Pectin modifications and the role of pectindegrading enzymes during postharvest softening of Jonagold apples. Food Chem 158, 283-91.

Jo WS, Song HY, Song NB, Lee JH, Min SC, and Song KB (2014) Quality and microbial safety of 'Fuji' apples coated with carnauba-shellac wax containing lemongrass oil. LWT-Food Sci Technol 55, 490-7.

Kim IH, Lee H, Kim JE, Song KB, Lee YS, Chung DS et al. (2013) Plum coatings of lemongrass oil-incorporating carnauba wax-based nanoemulsion. J Food Sci 78, E1551-9.

Mantilla N, Castell-Perez ME, Gomes C, and Moreira RG (2013) Multilayered antimicrobial edible coating and its effect on quality and shelf-life of fresh-cut pineapple (Ananas comosus). LWT-Food Sci Technol 5, 37-43.

Mehyar GF, El Assi NM, Alsmairat NG, and Holley RA (2014) Effect of edible coatings on fruit maturity and fungal growth on Berhi dates. Int $J$ Food Sci Tech, in press.

Mpho M, Sivakumar D, Sellamuthu PS, and BautistaBaños S (2013) Use of lemongrass oil and modified atmosphere packaging on control of anthracnose and quality maintenance in avocado cultivars. J Food Quality 36, 198-208.

Park HG, Lim BS, and Park YM (2009) Effects of 1-methylcyclopropene treatment and controlled atmosphere storage on poststorage metabolism and quality of 'Hongro' apples. Hort Environ Biotechnol 50, 313-8.

Park YM and Park HG (2012) Potential of initial CA condition on quality maintenance of 'Fuji' apples during export simulation after long-term storage. Korean J Hort Sci Technol 30, 400-8.

Parra J, Ripoll G, and Orihuel-Iranzo B (2014) Potassium sorbate effects on citrus weight loss and decay control. Postharvest Biol Tec 96, 7-13.

Perdones A, Sánchez-González L, Chiralt A, and Vargas M (2012) Effect of chitosan-lemon essential oil coatings on storage-keeping quality of 
strawberry. Postharvest Biol Tec 70, 32-41.

Sánchez-González L, Pastor C, Vargas M, Chiralt A, González-Martínez C, and Cháfer M (2011) Effect of hydroxypropylmethylcellulose and chitosan coatings with and without bergamot essential oil on quality and safety of cold-stored grapes. Postharvest Biol Tec 60, 57-63.

Shao XF, Tu K, Tu S, and Tu J (2012) A combination of heat treatment and chitosan coating delays ripening and reduces decay in "Gala" apple fruit. J Food Quality 35, 83-92.
Xing Y, Li X, Xu Q, Yun J, Lu Y, and Tang Y (2011) Effects of chitosan coating enriched with cinnamon oil on qualitative properties of sweet pepper (Capsicum annuum L.). Food Chem 124, 1443-50.

Zambrano-Zaragoza ML, Mercado-Silva E, Ramirez-Zamorano P, CornejoVillegas MA, Gutiérrez-Cortez E, and Quintanar-Guerrero D (2013) Use of solid lipid nanoparticles (SLNs) in edible coatings to increase guava (Psidium guajava L.) shelf-life. Food Res Int 51, 946-53. 